\title{
Comparativo entre o teste de Vicat e a calorimetria semi-adiabática para determinação do tempo de início e fim de pega em cimentos Portland
}

\author{
Comparison between the Vicat test and the \\ semi-adiabatic calorimetry to determine the \\ set time of Portland cements
}

\author{
Maycon Jonas Consalter Viecili ${ }^{1}$, Daniel Hastenpflug ${ }^{1}$, \\ Ricardo Girardi ${ }^{1}$
}

\footnotetext{
${ }^{1}$ Faculdade de Engenharia Civil, Faculdade de Engenharia (FENG)/PUCRS. Av. Ipiranga 6681, Prédio 30, Partenon Porto Alegre, RS, Brasil.

e-mail: maycon.viecili@acad.pucrs.br,daniel.hastenpflug@pucrs.br; ricardo.girardi@pucrs.br
}

\begin{abstract}
RESUMO
O objetivo deste trabalho foi de comparar dois métodos (Agulha de Vicat e Calorimetria Semi-Adiabática) para determinar o tempo de início e fim de pega do cimento Portland. Foram coletadas 10 amostras de 2 tipos de cimento com maior emprego na região sul do país de uma mesma unidade de fabricação, durante o mesmo mês. Verificou-se que o método de calorimetria semi-adiabática é uma técnica eficaz, prática e simples para monitorar o comportamento do processo de hidratação do cimento e fornecer resultados com variações de $1,5 \%$ (4 minutos) para o cimento CP II F-40 e de 6,3\% (14 minutos) para o CP V. Esta diferença de resultados pode ser explicada por alguma imprecisão durante a realização do ensaio de Vicat, ou a necessidade de uma maior quantidade de repetições de ambos os ensaios para se trabalhar com valores médios, mais aproximados. O tamanho das amostras testadas, também, impossibilita a aplicação das curvas apresentadas neste trabalho como padrão de comportamento para os cimentos estudados, visto que existe variabilidade de composição entre cada lote e cada fabricante.
\end{abstract}

Palavras-chave: Tempo de Pega; Ensaio de Vicat; Calorimetria Semi-adiabática.; Cimento CP II F-40; Cimento CP V ARI-RS

\section{ABSTRACT}

The objective of this work was to compare two methods (Vicat needle and semi-adiabatic calorimeter) to determine the cement set times. Ten samples of the 2 largest used types of cement were collected in the brazil's southern region of the same manufacturing unit during the same month. It was verified that the semiadiabatic calorimetry method is an efficient, practical and simple technique to monitor the behavior of the cement hydration process and to provide results with times varying $1.50 \%$ (4 minutes) for the CP II F- 40 and $6.28 \%$ (14 minutes) for CP V ARI-RS. This difference in results may be explained by some inaccuracy during the Vicat needle methods, or the need for a greater number of replicates of both methods to work with approximate mean values. The size of the samples tested also makes it impossible to apply the curves presented in this work as behavioral pattern for the studied cements, since there is variability of composition between each batch and each manufacturer.

Keywords: Set Times; Vicat needle; Semi-Adiabatic Calorimetry; Cement CP II F-40; Cement CPV ARI-RS

\section{INTRODUÇÃO}

A produção de concreto dosado em centrais vem batendo recorde, para suprir esta demanda à indústria de cimento vem aumentando sua produção. Dados do Sindicato Nacional da Indústria do Cimento (SNIC) [1] apontam para um crescimento de $50 \%$ da produção de cimento entre os anos de 2007 e 2013. Junto com este aumento, cresce as reclamações de problemas de pega, tempo de lançamento e endurecimento do concreto entregue em obra, fato este muitas vezes não explicado ou compreendido pelos fornecedores de concreto. 
Para evitar possíveis problemas, a maioria das empresas fornecedoras de concreto realizam o controle de recebimento de suas matérias primas para evitar variações de desempenho do produto final. Diariamente são feitas inspeções visuais nos agregados recebidos e mensalmente amostras são encaminhadas para laboratórios terceirizados para ensaios de caracterização com objetivo de avaliar a uniformidade do fornecimento. Nos aditivos, o controle é feito através de verificações de densidade no recebimento dos lotes, e no cimento, este controle resume-se no armazenamento das amostras coletadas para ensaios em laboratório terceirizados quando se identifica algum problema em obra. (ABESC, s.d. [2])

Os ensaios mais usuais em cimento avaliam as propriedades químicas como perda ao fogo, quantidades de gipsita e resíduos insolúveis na mistura, propriedades físicas tais como o tamanho grão definido através do processo de peneiramento em malha de abertura definida, superfície especifica, tempos de pega e propriedades mecânicas no caso ensaios de resistência a compressão. Estes ensaios, quando realizados, podem assegurar certo nível de uniformidade nos lotes de cimento recebido, em especial o ensaio de pega, realizado para controlar os teores de gipsita presente na mistura. Quantidades de gesso, finura muito diferentes em um mesmo tipo de cimento podem ocasionar comportamentos distintos de pega e endurecimento (METHA e MONTEIRO, 1994 [3]). O conhecimento destas informações possibilita a tomada de decisão quanto a possíveis correção nos traços de concreto a serem produzidos com este cimento.

O ensaio utilizado para determinar os tempos de início e final de pega preconizado pela norma brasileira é o Método da agulha de Vicat (NBR NM 65 (ABNT, 2003) [4]). Entretanto, devido à falta de equipamento, estrutura de laboratório e a deficiência de técnico treinado, aliado ao longo tempo de execução do ensaio, é impossível empregar essas metodologias para testar todos os lotes de cimento recebidos em uma central dosadora de concreto, devido à grande quantidade de aglomerante empregado. Nesse sentido, muitas das centrais fornecedoras coletam amostras aleatórias de cimento Portland, referente ao a esse insumo adquirido, deixando acondicionadas em seu laboratório para eventuais investigações por via de problemas ocorridos no concreto ou argamassa assim dosados.

Para contornar esta dificuldade, muitos profissionais empregam uma metodologia que não é normatizada, a calorimetria semi-adiabática, por causa da rapidez dos resultados e menor necessidade de trabalho humano no método. Esse método baseia-se no calor liberado durante a hidratação do cimento e segundo Neville (2013) [5], o início da pega é o ponto correspondente a final do período de indução, quando ocorre acentuada elevação da temperatura e o fim de pega corresponde ao pico de temperatura liberada durante o processo da hidratação do cimento.

Este trabalho busca estudar uma das alternativas práticas empregadas para avaliar o início e o fim de pega: a calorimetria semi-adiabática. Foram testados dois tipos de cimento com maior emprego na região sul, correlacionando as curvas de evolução de calor com os tempos de início e fim de pega obtido através do ensaio segundo NBR NM 65 (ABNT, 2003) [4].

\section{REFERENCIAL TEORICO}

\subsection{Hidratação do cimento Portland}

O cimento Portland é constituído de compostos anidros que em contato com a água adquirem propriedades ligantes e resistência mecânica. Ao passar do tempo estes apresentam característica que levam ao enrijecimento e posteriormente o endurecimento da pasta de cimento (MEHTA e MONTEIRO, 1994 [3]; NEVILLE, $2013[5])$.

De acordo com Neville (2013) [5], são duas as maneiras que os compostos de cimento reagem com a água. A primeira refere-se à própria reação de hidratação do cimento, que ocorre pela incorporação de moléculas de água, e a segunda acontece por hidrólise onde ocorre a quebra e dissolução de determinados componentes do cimento. Neville (2013) [5] complementa que é usual utilizar o termo hidratação do cimento para todas as reações com a água, isto é, tanto à hidratação como a hidrólise.

Já Mehta e Monteiro (1994) [3], explica que esse mecanismo de hidratação está baseado em duas outras formas, a hidratação por dissolução-precipitação e por topoquímico ou hidratação no estado sólido. A primeira envolve a dissolução de compostos anidros em constituintes iônicos, formação de hidratos na solução e possível precipitação de hidratos oriundo da solução supersaturada. Enquanto na topoquímico as reações ocorrem diretamente na superfície dos componentes anidro do cimento sem entrarem em solução.

Como o cimento Portland é constituído de vários compostos, que se hidratam em velocidades diferentes, pesquisas passaram a ser realizadas em separado de cada constituinte mineralógicos do clínquer Portland. De acordo com Mehta e Monteiro (1994) [3], os aluminatos presentes no clínquer acabam hidratando com 
maior velocidade que os silicatos. Já os silicatos compõem aproximadamente $75 \%$ do cimento Portland, estes têm papel importante nas características de endurecimento (taxa de desenvolvimento da resistência).

A reação do $\mathrm{C}_{3} \mathrm{~A}$ com água é imediata. Já a hidratação da alita $\left(\mathrm{C}_{3} \mathrm{~S}\right)$ ocorre em poucas horas e é responsável pela liberação de calor, enquanto na belita $\left(\mathrm{C}_{2} \mathrm{~S}\right)$ o processo de hidratação é mais lento podendo durar semanas (MEHTA e MONTEIRO, 1994 [3]; PETRUCCI, 1998 [6]).

As reações de hidratação do cimento Portland são exotérmicas, sendo a quantidade de calor liberada em joules por grama de cimento anidro, desenvolvida depois da completa hidratação a uma dada temperatura denominada como calor de hidratação (NEVILLE,2013 [5]). A informação da taxa de calor liberado pode ser utilizada para avaliar a reatividade dos cimentos Portland e acompanhar uma possível variação de produção no recebimento do cimento. As curvas esquemáticas de taxa de liberação de calor estão representadas na Figura 1.

Segundo Vernet [7] (1995 citado por AITCIN, 2000 [8]), são cinco os estágios iniciais da hidratação do cimento Portland: O estágio I, denominado período de mistura, os diferentes íons liberados pelas diversas fases $\left(\mathrm{C}_{3} \mathrm{~A}\right.$ e $\left.\mathrm{C}_{3} \mathrm{~S}\right)$ entram em solução, isto faz com que ocorra uma rápida evolução de calor durante poucos minutos. Esta dissolução é exotérmica e gera dois hidratos de reação rápida, silicato de cálcio hidratado e etringita, e nesse estágio a superfície das partículas de cimento é parcialmente coberta com os mesmos.

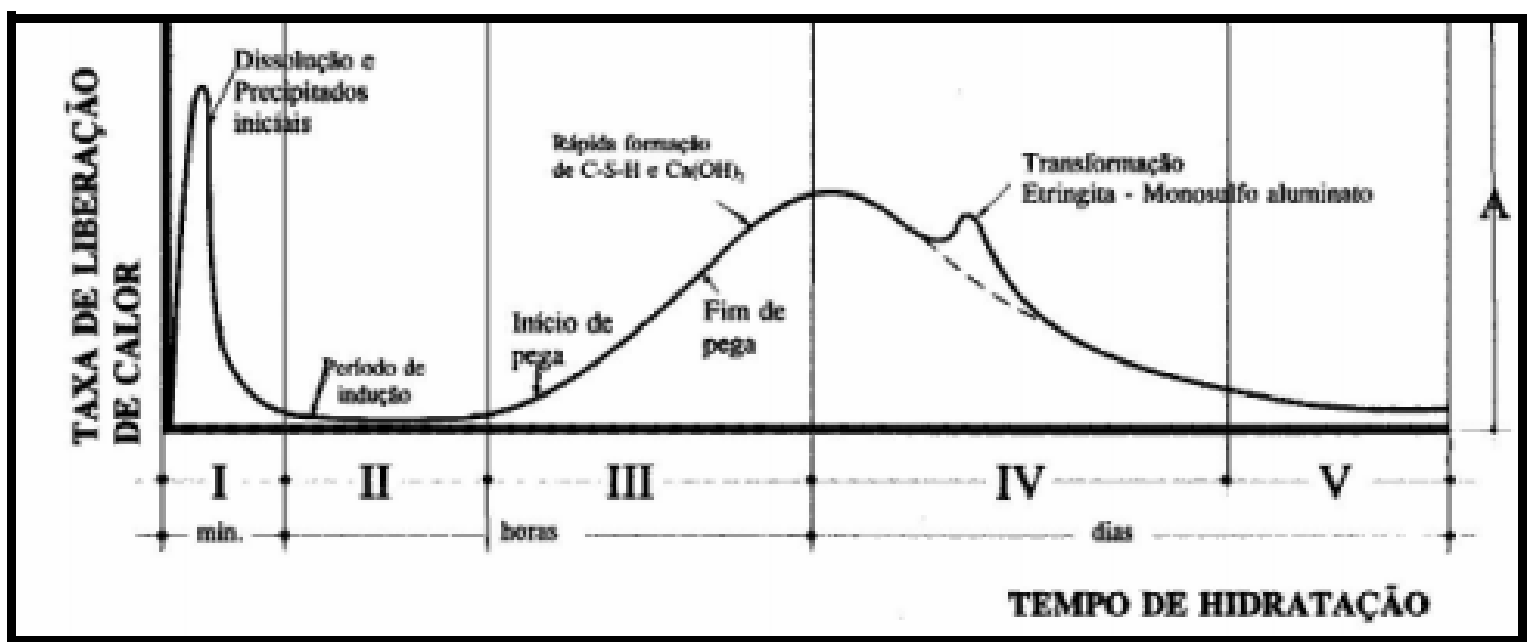

Figura 1: Representação esquemática da liberação de calor durante a hidratação do cimento Portland Jawed; Skalny (1989 citado por QUARCIONI, 2008, p. 8 [9]).

O estágio II, chamado de período de indução, o fluxo térmico fica consideravelmente mais lento, uma pequena quantidade de C-S-H é formada e existe um equilíbrio entre os íons de alumínio e de sulfato (NEVILLE, 2013 [5]).

Vernet [7] (1995 citado por AITCIN, 2000 [8]), seguiu dizendo que o estágio III, refere-se ao início da pega, a hidratação é ativada quando o óxido de cálcio começa a precipitar-se devido à falta de silicato na fase aquosa. O fluxo térmico cresce lentamente no início e acelera nos estágios finais. Esta elevação de calor ocorre devido a formação de Portlandita (hidróxido de cálcio, $\mathrm{CH}$ ), nos poros preenchidos de água, e de C-SH depositado em torno dos grãos do cimento (SOUZA, 2007 [10]).

Já o estágio IV, a etringita torna-se fonte de sulfato para formar monossulfoaluminato com a fase aluminato remanescente, essa reação gera calor e eleva a aceleração da hidratação das fases silicato. Vernet [7] (1995 citado por AITCIN, 2000 [8]) finaliza explicando que no V e último estágio os grãos de cimentos estão cobertos por uma camada de hidratos, e que com o passar do tempo, esta camada vai se tornando mais espessa e com isto a água vai tendo dificuldades de chegar nas partes não hidratadas.

Segundo Aïtcin (2000) [8], a hidratação do cimento Portland encerra quando não existe mais fase anidra de cimento, ou quando a água não puder chegar às fases não hidratadas, devido a matriz cimentícia muito densa, originada pelos compostos hidratados, ou quando a relação água/cimento é muito baixa e não exista mais água disponível para hidratação. Para uma melhor compreensão da hidratação do cimento o entendimento dos dois principais produtos hidratados, o silicato de cálcio hidratado e o aluminato tricálcicos hidratados são fundamentais.

Hastenpflug (2012) [11] segue informando que é usual atribuir o final da hidratação aos 28 dias de idade, devido ao fato da pasta já ter adquirido a resistência desejada. Porém, a hidratação acaba quando não 
existe mais fase anidra ou quando a água não pode mais chegar às fases não hidratadas.

Para evitar um enrijecimento imediato da pasta e viabilizar a utilização deste cimento Portland na construção civil, adiciona-se sulfato de cálcio ou gipsita em proporções adequadas (MEHTA et al, 1994 [3]). Neville (2013) [5] salienta que, a quantidade de gipsita deve ser dosada com cuidado, quando em excesso pode causar expansão e desagregação da pasta de cimento após a pega, sendo seu teor ótimo presente na mistura determinado através das quantidades de $\mathrm{SO}_{3}$ na mistura e também pela observação do desprendimento de calor de hidratação. Sendo que este último método não é normatizado.

A finura é fator que influencia na velocidade de hidratação do cimento, seu aumento propicia melhora no desempenho mecânico nas primeiras idades, aumentando também a trabalhabilidade, coesão e reduzindo a segregação. No entanto alguns limitadores devem ser levados em conta quanto a finura do cimento que variam desde o custo operacional do processo de moagem a quantidade de calor de hidratação liberado (NEVILLE, $2013[5])$.

\subsection{Pega e Endurecimento}

Segundo Neville (2013) [5], o termo pega é utilizado para descrever o período de início do enrijecimento da pasta de cimento, ou em outras palavras o momento em que a pasta deixa de ser plástica e passa a estar em um estado rígido. Posteriormente ao enrijecimento ocorre um aumento brusco de temperatura, neste momento a pasta de cimento solidifica e se torna não mais trabalhável, podendo ser chamada de início de pega (MEHTA et al., 1994 [3]). Já o final da pega ocorre no momento em que a pasta de cimento passa a não mais sofrer deformações e se solidifica por completo (MEHTA et al., 1994 [3], PETRUCCI, 1998v [6]).

Alguns fatores podem interferir no tempo de pega de um cimento, segundo Petrucci (1998) [6], a quantidades de $\mathrm{C}_{3} \mathrm{~A}$ presente no cimento pode acelerar a pega rapidamente, enquanto adições de gipsita em excesso retardam o início da pega. $\mathrm{O}$ grau de finura influencia na velocidade de reações do aglomerante.

\subsubsection{Métodos de verificação dos tempos de início e final de pega}

\subsubsection{Aparelho de Vicat}

A partir do instante em que a água entra em contato com o cimento na mistura destinada a determinar a consistência normal, ocorrem às reações de pega e enrijecimento explicadas por (MEHTA et al., 1994 [3]). Para determinar esta consistência é utilizado a sonda de Tetmajer instantes após o término da mistura, a pressão exercida pela sonda sobre a pasta é de $300 \mathrm{~g}$ sobre uma área de $0,786 \mathrm{~cm}^{2}$. Porém para caracterizar o processo de enrijecimento progressivo da pasta com o tempo é necessário substituir a sonda de Tetmajer por outra com área transversal menor denominada agulha de Vicat.

Esta agulha tem seção de $1 \mathrm{~mm}^{2}$ e atua com pressão de $23,58 \mathrm{~kg}$ sobre a mesma área de $0,786 \mathrm{~cm}^{2}$. No decorrer do ensaio dois pontos são bem característicos e nestes ocorrem mudanças bruscas na reologia da pasta de cimento. O primeiro ocorre um aumento da viscosidade da pasta conhecido como início de pega, geralmente é percebido a partir de 150 minutos da adição da água na pasta. O segundo ponto conhecido como fim da pega ocorre à passagem do estado plástico para o estado sólido.

\subsubsection{Calorimetria semi-adiabática}

Segundo Souza (2007) [10], a calorimetria semi-adiabática, mede o acréscimo de temperatura produzida pelas reações no decorrer do tempo. A diferença entre a denominação de adiabático para semi-adiabático devese ao fato de que na calorimetria adiabática considera-se que a perda de calor para o meio é muito pequena, e assim o corpo de prova pode ser considerado isolado, sendo a evolução da temperatura atribuída ao calor de hidratação.

Nos calorímetros semi-adiabático existem trocas de calor com o ambiente, sendo necessário conhecer a capacidade térmica do calorímetro para determinar a quantidade de calor gerado a partir da hidratação do cimento. Através das curvas semi-adiabáticas de calor liberado versus tempo de hidratação do cimento, podese avaliar o período de indução, o calor liberado no período de hidratação, a desaceleração desta evolução de calor e os tempos em que isto ocorre.

Com base nas curvas geradas é possível observar que em ambos os casos o início de pega corresponde ao término do período dormente (estágio II), neste momento ocorre pequena elevação da temperatura. No entanto, diferente dos estudos realizados por Taylor (1990) [12]; Mehta et al. (1994) [3]; Neville (2013) [5] que informam o fim de pega ocorrendo na máxima taxa de elevação de temperatura após o período de indu- 
ção (figura 02), neste estudo verificou-se que o ponto de fim de pega corresponde ao início do estágio III ou período de aceleração, aproximadamente 1 hora após seu início. Sandberg e Liberman (2007) [13] mostra que o tempo de final de pega pode variar em $\pm 20 \%$. Este resultado está próximo aos estudos realizados por Hamachandran (1984) [14]; Jawed; Skalny e Young (1983) [15] onde o fim de pega foi localizado na metade do período de aceleração (Figura 2).

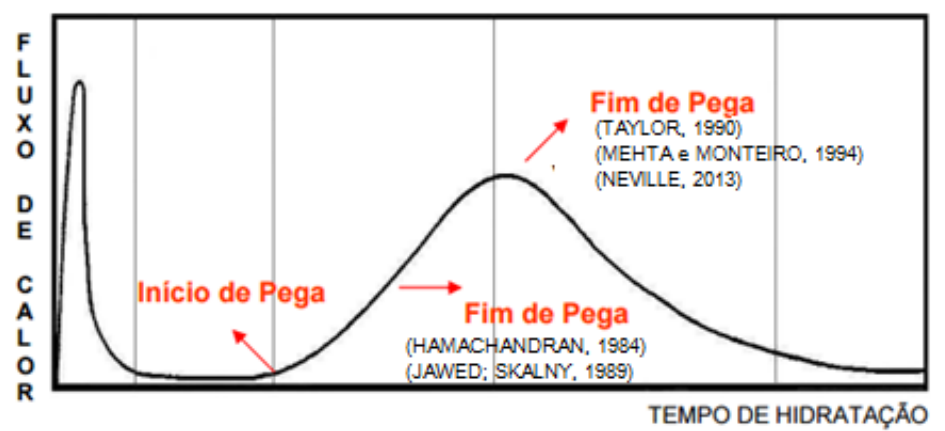

Figura 2: Localização dos tempos de pega na curva de evolução de calor.

A partir destas curvas, pode-se determinar os tempos de início e final de pega de duas maneiras: Método das Frações Diretas (WEAKLEY, (2010) [16]) e o método das derivadas (Sandberg e Liberman, 2007 [13]). No primeiro, os tempos em questão são definidos como percentuais do aumento de temperatura total. Em condições de ambiente controlado, o percentual de início de pega é $21 \%$, enquanto o de fim de pega é $42 \%$ (Figura 3).

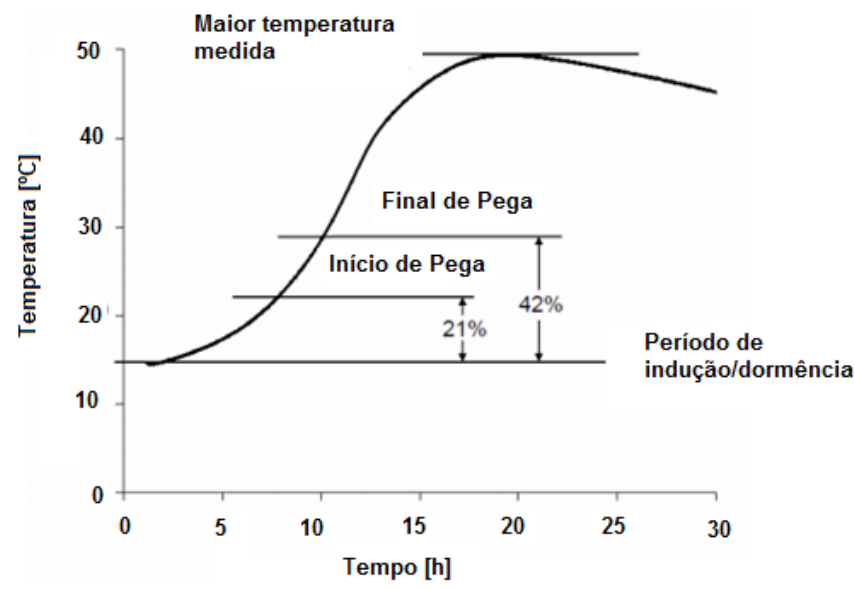

Figura 3: Início e final de pega definido através do método das Frações Diretas (SANDBERG e LIEBERMAN citado por WEAKLEY (2010, p. 42) [16])

Sandberg e Liberman (2007) [13] observaram que o tempo início de pega pode ser determinado pelo tempo onde ocorre o maior pico de temperatura da segunda derivada da curva temperatura em relação ao tempo determinada pelo ensaio de calorimetria adiabática (Figura 4). Já o tempo de final de pega é dado pelo pico da primeira derivada (Figura 4) 

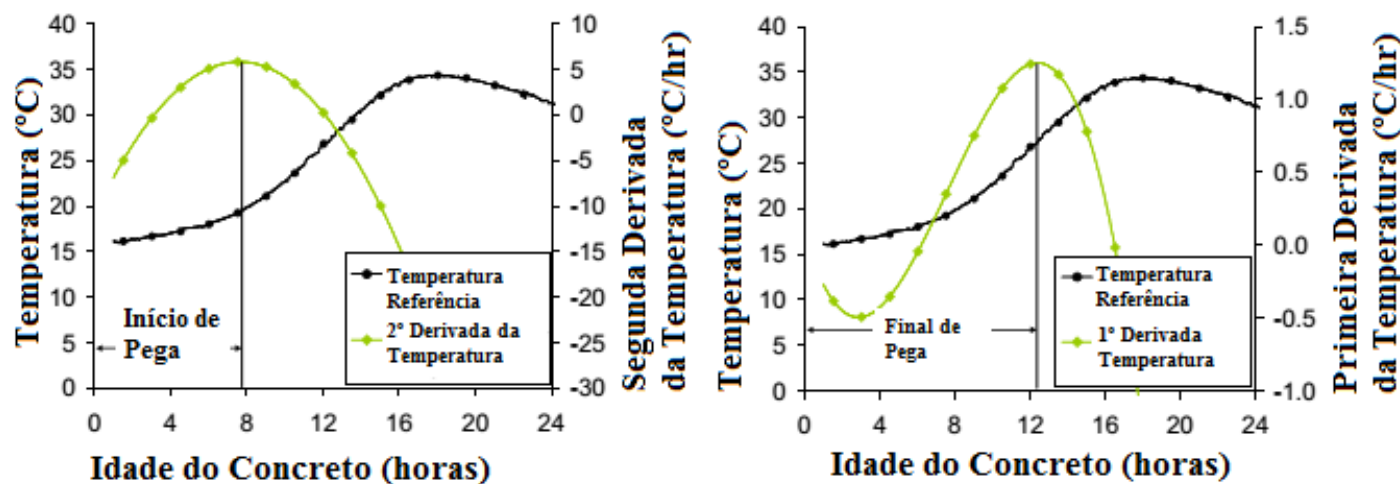

Figura 4: Determinação dos tempos de início e final de pega pelo método das derivadas. Primeira derivada: Final de pega; Segunda derivada: início de pega ( Sandberg e Liberman (2007) [13])

\section{MATERIAIS E MÉTODOS}

Para se comparar os resultados obtidos pelo o ensaio de calorimetria semi-adiabática e o teste de Vicat, em relação aos tempos de início e final de pega, foram testadas pastas de cimento. A seguir foram realizados os tratamentos apresentados na revisão bibliográfica e comparou-se os resultados.

\subsection{Cimentos empregados}

Empregou-se os cimentos os cimentos CPII F -40 e CPV-ARI RS, fabricados no mês de março de 2015. Os resultados dos ensaios químicos, físicos e mecânicos fornecido pelo fabricante, estão representados nos Quadros 1 e 2 .

Tabela 1: Resultados dos ensaios químicos, físicos e mecânicos do Cimento CP II-F 40

\begin{tabular}{|c|c|c|c|c|c|c|c|c|c|c|c|c|c|}
\hline \multicolumn{14}{|c|}{ Ensaios em cimento CPII -F 40} \\
\hline & \multicolumn{4}{|c|}{ Teores $(\%)$} & \multicolumn{2}{|c|}{ Finura $(\%)$} & \multirow{2}{*}{$\begin{array}{l}\text { Blaine } \\
\left(\mathrm{cm}^{2} / \mathrm{g}\right)\end{array}$} & \multicolumn{2}{|c|}{ Tempos de pega } & \multicolumn{4}{|c|}{ Resistência a compressão } \\
\hline & $\mathrm{PF}$ & $\mathrm{MgO}$ & $\mathrm{SO}_{3}$ & RI & \#200 & \#325 & & $\begin{array}{l}\text { Início } \\
\text { (min) }\end{array}$ & $\begin{array}{l}\text { Fim } \\
\text { (min) }\end{array}$ & 1 dia & 3 dias & 7 dias & 28 dias \\
\hline $\begin{array}{l}\text { Limites de } \\
\text { Norma }\end{array}$ & $\leq 6,5$ & $\leq 6,5$ & $\leq 4,0$ & $\leq 2,5$ & $\leq 10,0$ & N/A & $\geq 2800$ & $\geq 60$ & $\leq 600$ & N/A & $\geq 15,0$ & $\geq 25,0$ & $\geq 40$ \\
\hline Média & 5,09 & 6,02 & 3,39 & 0,93 & 0,00 & 0,38 & 4720 & 212 & 275 & 25,6 & 35,2 & 39,6 & 45,8 \\
\hline $\begin{array}{l}\text { Desvio } \\
\text { Padrão }\end{array}$ & 0,24 & 0,17 & 0,19 & 0,10 & 0,00 & 0,16 & 138 & 19 & 22 & 1,23 & 1,21 & 1,10 & 1,22 \\
\hline Mínimo & 4,72 & 5,66 & 2,28 & 0,8 & 0,00 & 0,20 & 4330 & 180 & 240 & 23,7 & 33,1 & 37,5 & 44.0 \\
\hline Máximo & 5,76 & 6,41 & 3,77 & 1,2 & 0,00 & 0,70 & 4960 & 240 & 310 & 28,7 & 37,1 & 42,2 & 48,6 \\
\hline
\end{tabular}

Tabela 2: Resultados dos ensaios químicos, físicos e mecânicos do Cimento CP V-ARI RS

\begin{tabular}{|c|c|c|c|c|c|c|c|c|c|c|c|c|c|}
\hline \multicolumn{14}{|c|}{ Ensaios em cimento CPV - ARI RS } \\
\hline & \multicolumn{4}{|c|}{ Teores $(\%)$} & \multicolumn{2}{|c|}{ Finura $(\%)$} & \multirow{2}{*}{$\frac{\text { Blaine }}{\left(\mathrm{cm}^{2} / \mathrm{g}\right)}$} & \multicolumn{2}{|c|}{ Tempos de pega } & \multicolumn{4}{|c|}{ Resistência a compressão } \\
\hline & $\mathrm{PF}$ & $\mathrm{MgO}$ & $\mathrm{SO}_{3}$ & RI & \#200 & \#325 & & $\begin{array}{l}\text { Início } \\
\text { (min) }\end{array}$ & $\begin{array}{l}\text { Fim } \\
(\min )\end{array}$ & 1 dia & 3 dias & 7 dias & 28 dias \\
\hline $\begin{array}{c}\text { Limites } \\
\text { de Nor- } \\
\text { ma }\end{array}$ & $\leq 4,5$ & $\leq 6,5$ & $\leq 4,5$ & N/A & $\leq 6,0$ & N/A & $\geq 3000$ & $\geq 60$ & $\leq 600$ & $\geq 11,0$ & $\geq 24,0$ & $\geq 34,0$ & N/A \\
\hline Média & 3,4 & 5,5 & 3,3 & 12,4 & 0,1 & 1,0 & 5040 & 215 & 280 & 23,4 & 32,6 & 37,3 & 47,6 \\
\hline $\begin{array}{l}\text { Desvio } \\
\text { Padrão } \\
\end{array}$ & 0,4 & 0,2 & 0,2 & 2,0 & 0,1 & 0,4 & 137 & 13 & 15 & 1,3 & 1,2 & 1,2 & 1,0 \\
\hline Mínimo & 2,5 & 5,2 & 2,9 & 7,0 & 0,0 & 0,3 & 4800 & 200 & 260 & 20,9 & 30,6 & 35,1 & 45,3 \\
\hline Máximo & 4,2 & 5,9 & 3,7 & 16,5 & 0,1 & 1,8 & 5440 & 240 & 310 & 26,5 & 34,8 & 39,9 & 49,8 \\
\hline
\end{tabular}




\subsection{Determinação da água da pasta de consistência normal}

Para que a execução dos ensaios seja uniforme para todas as amostras de cimentos, de maneira que seja possível uma comparação de resultados, a viscosidade precisa ser igual para todas as amostras. Devido a isto não existe uma quantidade fixa de água que resulte na pasta de consistência normal para todas as classes de cimentos, sendo sua determinação feita experimentalmente.

Os ensaios foram realizados em ambiente climatizado com temperatura de $25 \pm 2{ }^{\circ} \mathrm{C}$ e umidade relativa maior que $50 \%$. Antes da realização dos ensaios as amostras de cimento e água permaneceram neste mesmo ambiente por aproximadamente 24 horas para atingir um equilíbrio térmico. Após este período as amostras foram pesadas e acondicionadas em embalagens plásticas com $1500 \mathrm{~g}$ de cimento. Os procedimentos adotados neste ensaio seguiram as orientações prescritas na NBR NM 43 (ABNT, 2003) [17].

Após a realização dos procedimentos, foi determinado que a relação/água cimento necessária para que a pasta alcance a consistência normal foi 0,29, tanto para o cimento CP II-F 40 quanto para o CP V - ARI RS.

\subsection{Determinação dos tempos de pega pelo método de Vicat}

Os procedimentos adotados neste ensaio seguiram as orientações prescritas na NBR NM 43 (ABNT, 2003) [17]. Para este ensaio os equipamentos utilizados e as condições ambientes foram as mesmas do ensaio de água da pasta de consistência normal, exceto a utilização das agulhas de Vicat ao invés da sonda de Tetmajer. Os procedimentos adotados no ensaio seguiram as orientações da NBR NM 65 (ABNT, 2003) [4].

\subsection{Calorimetria semi-adiabática}

A necessidade de determinar o início das reações de hidratação do cimento e assim correlacionar com os tempos de pega do cimento obtidos através do ensaio de Vicat, conduziu a realização de ensaios calorimétricos em pasta de cimento. Para este ensaio foi utilizado um sistema de aquisição de dados Pico Log, modelo TC-08 (figura 5a) conectado a um computador e termopares tipo k. Como não existe norma que regulamente os procedimentos de ensaio para calorimetria algumas premissas foram abordadas de modo a representar as mesmas condições do ensaio do aparelho de Vicat.

A pasta de cimento foi reproduzida conforme procedimento da NBR NM 43 (ABNT, 2003) [17], e com a mesma relação a/c da água de pasta de consistência normal do ensaio de Vicat. Com a amostra recém misturada era colocado $400 \mathrm{~g}$ de pasta em um recipiente cilíndrico de isopor em forma de copo. Após este processo, o recipiente foi mantido dentro de uma caixa de madeira em MDF com espessura de paredes de 1,5 $\mathrm{cm}$, altura de $20 \mathrm{~cm}$, comprimento de $70 \mathrm{~cm}$, preenchida internamente com uma placa de isopor de modo a acomodar os recipientes das amostras de ensaio. Esta caixa permaneceu em uma sala climatizada sendo sua temperatura mantida em $(23 \pm 2){ }^{\circ} \mathrm{C}$ e umidade relativa de $(55 \pm 5) \%$.

Com os recipientes preenchidos, o termopar era mantido na metade da amostra (figura $5 \mathrm{~b}$ ) e isolado com fita adesiva de modo a reduzir o fluxo de ar no espaço entre a tampa e o recipiente da amostra. A tampa da caixa também em madeira MDF foi revestida na parte interna com uma camada de $10 \mathrm{~cm}$ de isopor e com uma manta de alumínio. A passagem dos fios termopar para leitura da temperatura das amostras foram feitas através de uma pequena abertura lateral sem que houvesse perda de calor durante o ensaio.

$\mathrm{O}$ ensaio de calorimetria foi iniciado assim que as amostras foram despejadas e adensadas nos recipientes de ensaio e a tampa da caixa então fechada (figura 5c). O tempo desde o contato inicial do cimento com a água até o lançamento do ensaio de calor foi de 10 minutos. Sendo assim não possibilitou a determinação do primeiro pico de calor de hidratação (calor de dissolução) que ocorre nos primeiros minutos conforme informado por Vernet [7] (1995 citado por AITCIN, 2000 [8]). 


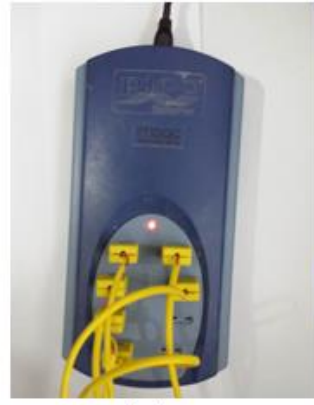

(a)

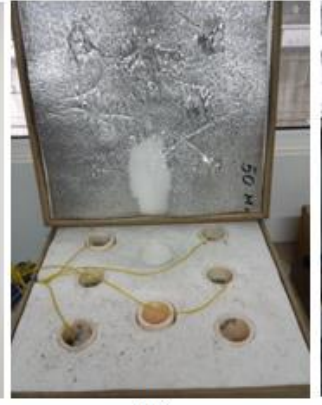

(b)

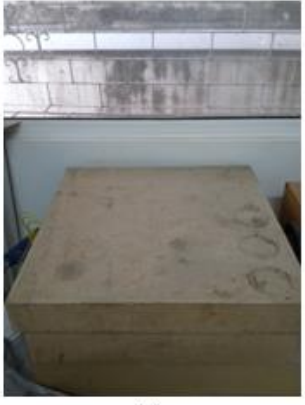

(c)

Figura 5: (a) sistema de aquisição de dados; (b) colocação dos termopares nos recipientes contendo amostra de ensaio; (c) ensaio em andamento.

\section{RESULTADOS}

Esta seção deverá apresentar todos os resultados obtidos com as informações necessárias para se verificar com A pesquisa baseou-se em analisar os resultados obtidos no ensaio de tempo de pega do cimento e correlacionar com seus respectivos gráficos de calor de hidratação. Ressalta-se que os ensaios foram realizados sempre pelo mesmo laboratorista em local com temperatura situada na faixa de $23 \pm 2{ }^{\circ} \mathrm{C}$, e que os equipamentos são calibrados periodicamente. A base de dados da pesquisa é composta por 15 amostras distribuídas em 3 tipos de cimento de uma mesma marca comercial e produzidas na mesma unidade no mesmo período. As amostras de cimento foram coletas de um mesmo do fabricante no estado do Rio Grande do Sul.

\subsection{Resultados de pega agulha de Vicat}

Na Tabela 3 consta as médias dos valores dos ensaios de tempo de pega realizados nas amostras coletadas de cada tipo de cimento conforme procedimento da NBR NM 65 (ABNT, 2003) [4], junto os valores médios dos ensaios realizados pelo fabricante do cimento.

Com base nestes valores é possível observar que os tempos de pega encontrados para os cimentos CPII F-40 e CPV-ARI RS estão próximos aos valores informados pelo fabricante. Pode-se afirmar, com 90\% de confiança, que os valores definidos comparados não apresentam diferença significativa.

Tabela 3: Valores nos ensaios de pega para cada tipo de cimento.

\begin{tabular}{c|c|c|c|c}
\hline \multicolumn{5}{c}{ Ensaio dos tempos de pega do cimento } \\
\hline \multirow{2}{*}{ Tipos de cimento } & \multicolumn{2}{|c}{ Valores médios do fabricante } & \multicolumn{2}{c}{ Valores médios do ensaio } \\
\cline { 2 - 5 } & $\begin{array}{c}\text { Início da } \\
\text { pega (min) }\end{array}$ & $\begin{array}{c}\text { Fim da pega } \\
\text { (min) }\end{array}$ & $\begin{array}{c}\text { Início da } \\
\text { pega (min) }\end{array}$ & $\begin{array}{c}\text { Fim da pega } \\
\text { (min) }\end{array}$ \\
\hline CPII F-40 & 210 & 275 & 215 & 265 \\
\hline CPV -ARI RS & 215 & 270 & 225 & 270 \\
\hline
\end{tabular}

\subsection{Análise das curvas semi-adiábaticas de elevação de temperatura}

As curvas de elevação de temperaturas determinadas pelo método de calorimetria semi-adiabática para os cimentos CPII F-40 e cimento CPV -ARI RS são apresentados na figura 6. As curvas apresentadas não apresentam período pré-indução pois existe uma perda de calor para o ambiente. 


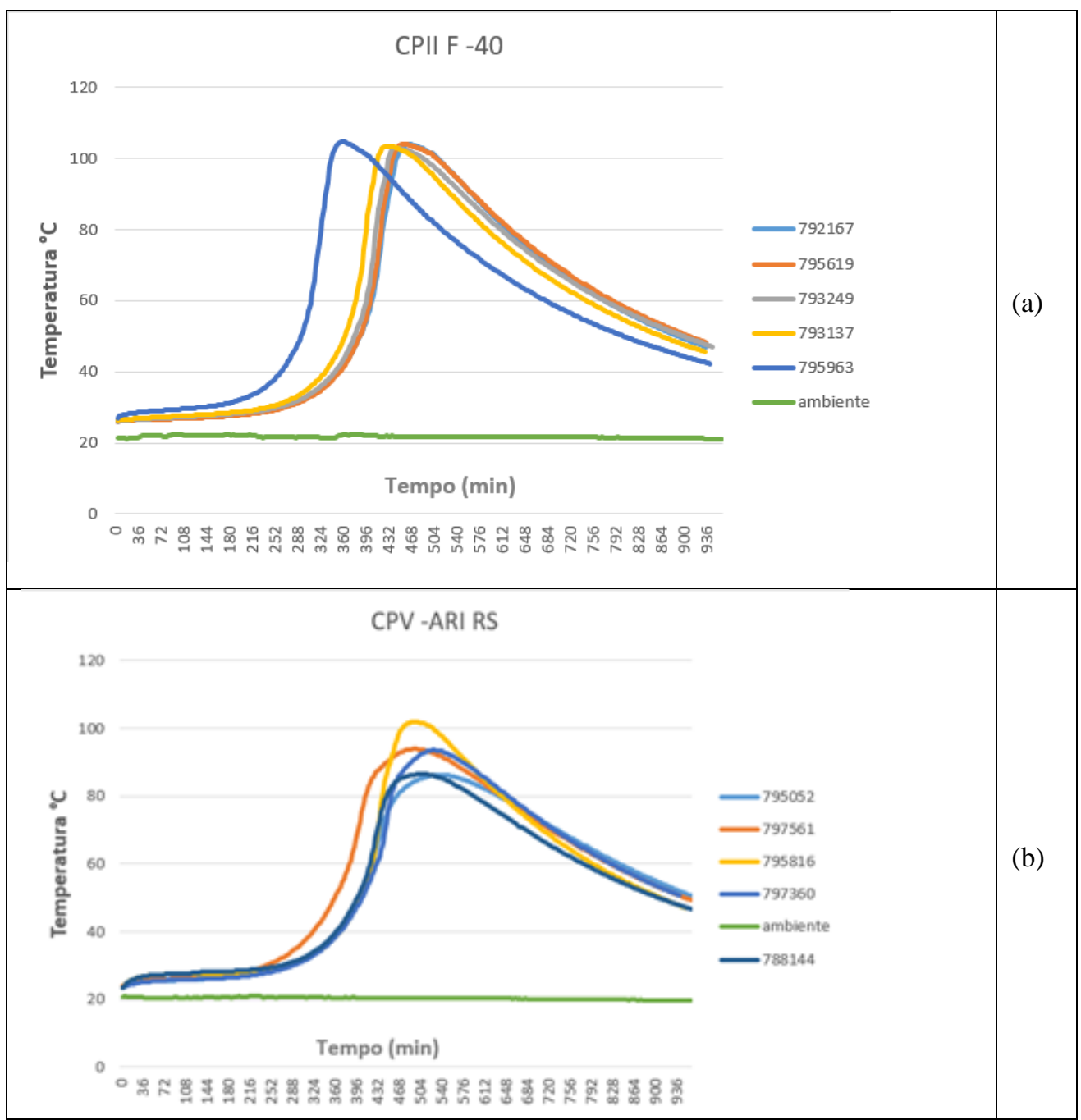

Figura 6: Curvas de Caloria semi-adiabáticas (a) CP II-F 40; (b) CP V-ARI RS.

Com base nos gráficos gerados, podemos observar comportamentos distintos das curvas de evolução da elevação de temperatura para cada tipo de cimento. O comportamento da evolução de temperatura no período dormente e de aceleração para o cimento CPV-ARI RS foram semelhando em todas amostras, porém ocorreu grande variação no pico de temperatura. Isto pode estar associado ao fato deste cimento apresentar teores de resíduos insolúveis na composição variando de 7,0 a 16,5\% conforme informado na Tabela 2.

Através das análises das curvas (Figura 6) foi tomado como base as curvas médias que melhor representaram cada classe de cimento e nestas curvas localizados os valores médios obtidos através do ensaio segundo a NBR NM 65 (ABNT, 2003) [4]. A metodologia de calorimetria semi-adiabática visa avaliar a localização dos tempos de pega obtidos pelo método normatizado e assim obter uma relação entre a hidratação do cimento com os tempos de pega.

Na Figura 7 é mostrado a curva média de cada tipo de cimento, com a localização dos seus respectivos valores de pega, determinados pelo método de Vicat. Observa-se que o ponto do início de pega determinado no método tradicional é o final do período de dormência/indução, como defendido por Taylor (1990) [12]; Mehta et al. (1994) [3]; Neville (2013) [5], entre outros. Já o final de pega foi atingindo em tempos muito menores que o tempo onde foi observado o ponto máximo de liberação de calor. Também acontece um pouco mais cedo que o que é indicado nos estudos de por Ramachandran (1984) [14] e Jawed, Skalny e Young (1983) [15].

Para os dois tipos de cimento avaliados o início da pega ocorreu no término do período dormente e o fim da pega no período de aceleração, aproximadamente 1 hora após seu início. A localização dos tempos de pega foi praticamente idêntica para cada um dos 2 tipos de cimento. Este fato pode estar relacionado ao um processo de fabricação com um mesmo lote de clínquer para ambos os cimentos. 


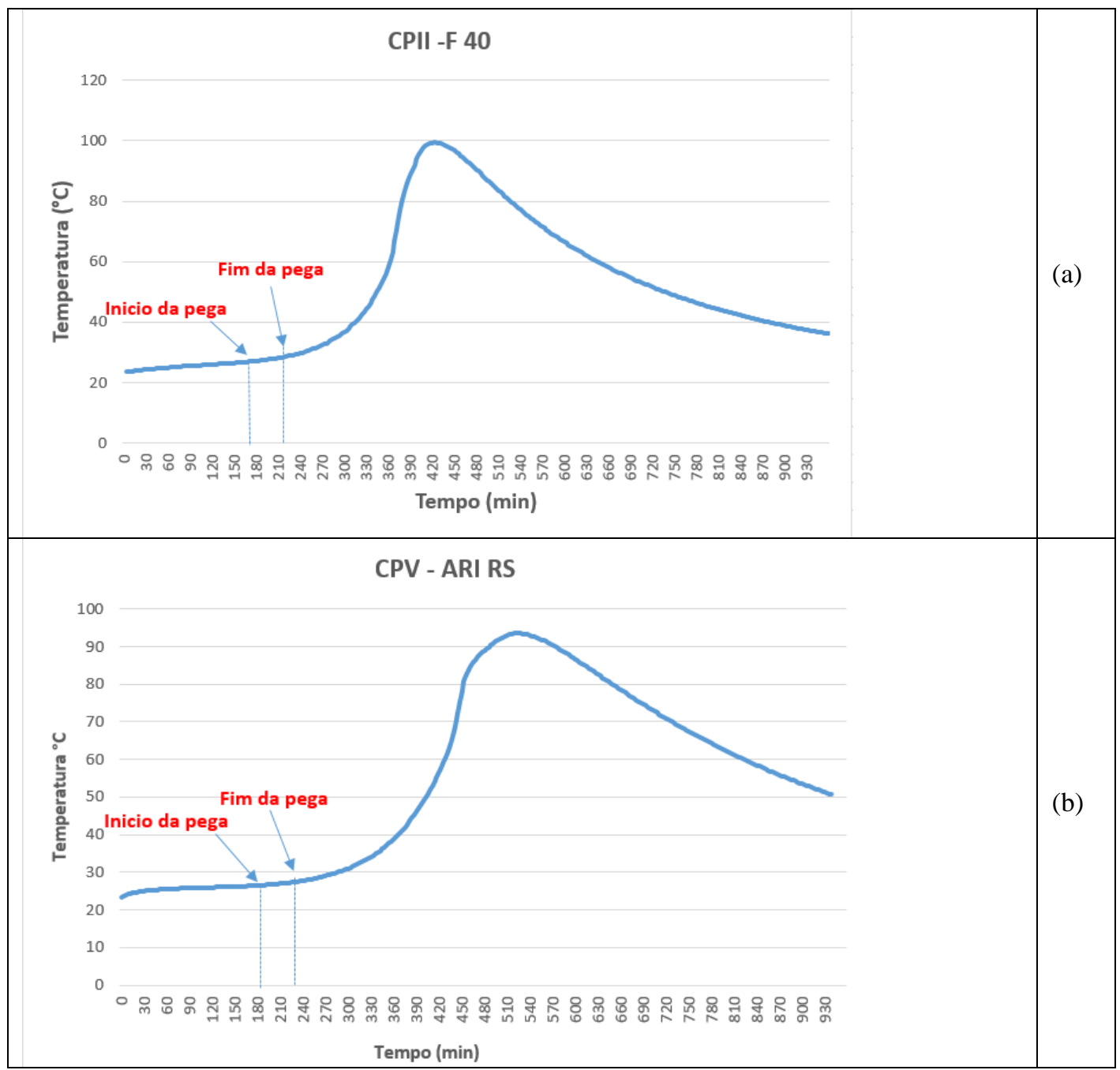

Figura 7: Curva padrão para as amostras de cimento a) CPII F-40; b) CPV - ARI RS.

\subsubsection{Método das Frações Diretas}

Os tempos de início e final de pega por este método foi definida pela determinação do aumento total da temperatura. Em seguida, foram determinados os valores de $21 \%$ e $42 \%$ e através da equação da reta foram determinados os tempos. Os índices estão representados na tabela 4.

Tabela 4: Início e Final de Pega pelo Método das Frações Diretas

\begin{tabular}{c|c|c|c|l|l|l|c}
\hline \multicolumn{5}{c|}{ Tempo de Pega [min]-Frações Diretas } & \multicolumn{2}{c}{ Tempo de Pega [min] } \\
\hline \multicolumn{1}{c}{ Cimento } & $\Delta \mathrm{T}\left[{ }^{\circ} \mathrm{C}\right]$ & $\mathrm{T} 21 \%\left[{ }^{\circ} \mathrm{C}\right]$ & $\mathrm{T} 42 \%\left[{ }^{\circ} \mathrm{C}\right]$ & Início & Final & Início & Final \\
\hline CP II F-40 & 75,52 & 43,47 & 59,32 & 370 & 405 & 215 & 265 \\
\hline CP V -ARI RS & 67,06 & 40,56 & 54,64 & 370 & 420 & 215 & 280 \\
\hline
\end{tabular}

Observa-se que os valores de início e final de pega, quando comparados com os valores obtidos com o método do Vicat são muito maiores. O cimento CP II F- 40 apresentou um incremento de 72,4\% para a indicação do início do tempo de pega, enquanto o final acontece em um período $54 \%$. Já para o cimento CP V ARI RS, os tempos de pega se iniciaram $73,0 \%$ mais tarde que o indicado pelo Vicat e terminaram $51,1 \%$ mais tarde. Com $90 \%$ de confiança, pode-se afirmar que os métodos apresentam valores que diferem significativamente.

Desta maneira, o método das frações diretas não se mostrou indicado, visto que os tempos de início e final de pega para todos os cimentos testados apresentaram início e final de pega 50\% mais demorados do 
que o observado durante o ensaio de Vicat. Vale lembrar que se fossem estabelecidos os tempos de pega indicados pelo método da fração, as operações de homogeneização, transporte, lançamento, adensamento e acabamento poderiam resultar em estruturas com desempenho insatisfatório.

\subsubsection{Método das Derivadas}

Os tempos de início e final de pega por este método foi definida pela determinação da equação da curva obtida pelo ensaio de calorimetria semi-adiabatica, usando um software que empregou as transformadas de Forier para o melhor ajuste. Com a ajuda da mesma ferramenta computacional se calculou as derivadas primeira e segunda. De posse destes resultados, plotou-se as curvas.

A Figura 8 (a) mostra a segunda derivada da curva para o cimento CPII F-40. O tempo onde se alcançou a temperatura máxima é o tempo de início de pega. Já o pico máximo da primeira derivada (Figura 8(b)) determina o tempo do final de pega.

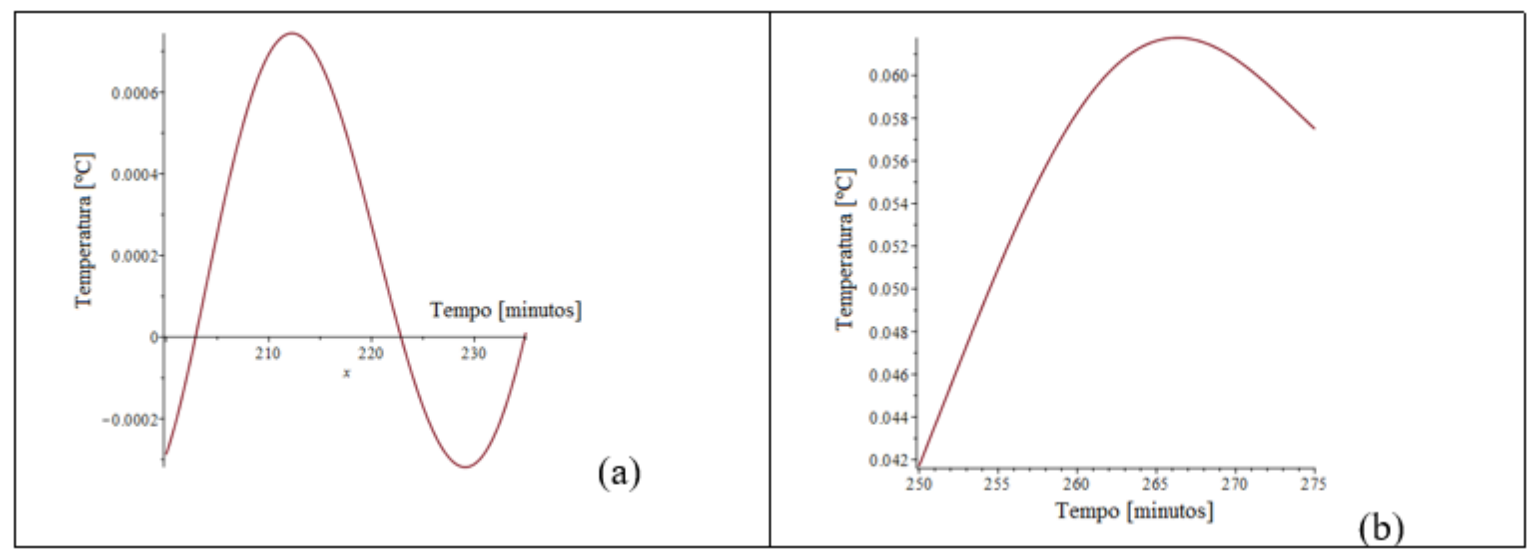

Figura 8: Método das derivadas para determinação de tempos de a) início de pega e b) final de pega para o CPII F-40

A Figura 9 (a) mostra a segunda derivada da curva para o cimento CPV-ARI RS. O tempo onde se alcançou a temperatura máxima é o tempo de início de pega. Já o pico máximo da primeira derivada (Figura 9(b)) determina o tempo do final de pega.

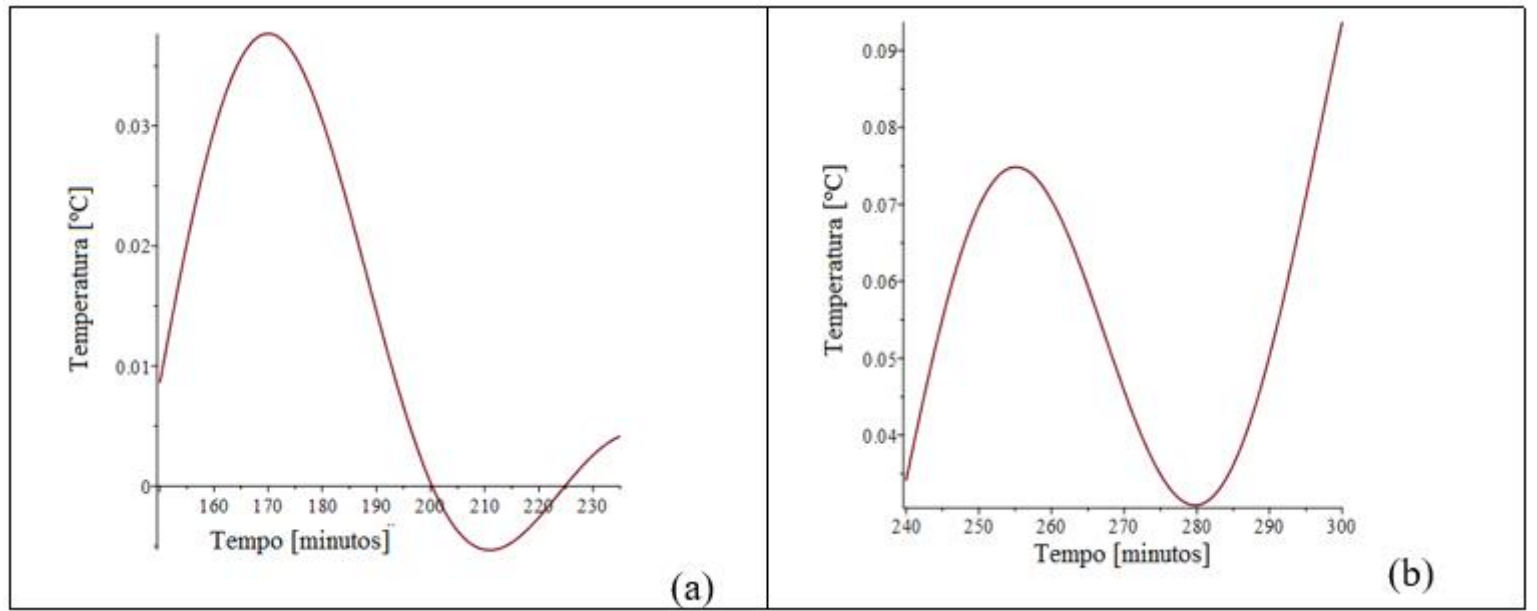

Figura 9: Método das derivadas para determinação de tempos de a) início de pega e b) final de pega para o CPV -ARI RS

Para facilitar a análise dos resultados, representou-se os tempos de início e final de pega dos cimentos testados no Tabela 5. Observa-se que os valores tempo de pega determinado pelo método das derivadas foram bastante próximos aos adquiridos pelo ensaio de Vicat. 
Tabela 5: Início e Final de Pega pelo Método das derivadas

\begin{tabular}{c|c|c|c|c|c|c}
\hline \multirow{2}{*}{ Tipos de cimento } & \multicolumn{2}{c|}{$\begin{array}{c}\text { Ealores médios do fabri- } \\
\text { cante }\end{array}$} & \multicolumn{2}{|c|}{ Valores médios do ensaio } & \multicolumn{2}{c}{$\begin{array}{c}\text { Valores Método das Deri- } \\
\text { vadas }\end{array}$} \\
\cline { 2 - 7 } & $\begin{array}{c}\text { Início da } \\
\text { pega (min) }\end{array}$ & $\begin{array}{c}\text { Fim da pega } \\
(\mathrm{min})\end{array}$ & $\begin{array}{c}\text { Início da } \\
\text { pega (min) }\end{array}$ & $\begin{array}{c}\text { Fim da pega } \\
(\mathrm{min})\end{array}$ & $\begin{array}{c}\text { Início da } \\
\text { pega (min) }\end{array}$ & $\begin{array}{c}\text { Fim da pega } \\
(\mathrm{min})\end{array}$ \\
\hline CPII F-40 & 210 & 275 & 215 & 265 & 215 & 270 \\
\hline CPV -ARI RS & 215 & 280 & 225 & 270 & 240 & 260 \\
\hline
\end{tabular}

Para o cimento CP II F-40 o tempo de pega foi exatamente igual. Já para o final de pega, determinouse um tempo 1,5\% maior (4 minutos depois). Nos ensaios conduzidos no cimento CP V-ARI, os resultados também se mostraram muito próximos aos determinados pelo ensaio de Vicat. O início de pega determinado ficou 6,28\% maior (14 minutos mais tarde) e o tempo do final de pega reduziu em 5,17\% (14 minutos mais cedo).

\section{CONCLUSÃO}

Frente aos resultados observados pode-se afirmar que a calorimetria semi-adiábatica mostrou-se um ensaio adequado para a determinação dos tempos de início e final de pega dos cimentos CP II F-40 e CP V - ARI RS. Entretanto, o método para a definição destes dados deve ser cuidadosamente definido.

Para os cimentos testados neste trabalho, o método de análise, a partir das derivadas da função polinomial proposta por Sandberg e Liberman (2007) [13] apresenta os melhores resultados para a estimativa dos tempos de início e final de pega, visto que apresenta pequenas variações de resultados, quando comparados com o Ensaio de Vicat. Acredita-se que a diferença de resultados pode ser explicada por alguma imprecisão durante a realização do ensaio de Vicat, visto que existe uma influência significativa do equipamento ou do seu operador. Também não se exime a necessidade de uma maior quantidade de repetições de ambos os ensaios para se trabalhar com valores médios, mais aproximados.

Não é possível aplicar as curvas apresentada neste trabalho como padrão de comportamento para cimentos fabricado em unidades diferentes. Isto porque o estudo abrange somente uma unidade de fabricação e dois tipos de cimento Portland, de fato não há dados suficientes que comprovem o mesmo comportamento para os demais fabricantes.

\section{BIBLIOGRAFIA}

[1] SINDICATO NACIONAL DA INDÚSTRIA DO CIMENTO (SNIC). Disponível em http://www.snic.org.br/historia.asp Acesso em: 23 de março de 2015.

[2] ASSOCIAÇÃO BRASILEIRA DAS EMPRESAS DE SERVIÇO DE CONCRETAGEM (ABESC). Disponivel em: http://www.abesc.org.br/concreteca/publicacoes/83/como-concretar.html Acesso em: 08 de abril de 2015 .

[3] MEhtA, P. K., MONTEIRO, P. J. M. Concreto: Estrutura, Propriedades e Materiais, São Paulo, Ed. PINI, 1994.

[4] ASSOCIAÇÃO BRASILEIRA DE NORMAS TÉCNICAS. NBR NM 65: Cimento Portland - Determinação do tempo de pega. Rio de Janeiro, 2003.

[5] NEVILLE, A. M. Tecnologia do concreto. Trad. de Ruy Alberto Cremonini, 2.ed. Porto Alegre, Bookman, 2013.

[6] PETRUCCI, ELÁDIO G. R. Concreto de Cimento Portland - 6 ${ }^{\mathrm{a}}$ Ed. - atualizada e rev. por Vladmir Antônio Paulon - Porto Alegre, 1978.

[7] VERNET, C. Mécanismes chimiques d'interactions ciment-adjuvants, CTG Sp. Guerville Service Phsyco-Chimie du Ciment, Janvier. 1995.

[8] AÏTCIN, P. Concreto de Alto Desempenho, Trad. de Geraldo G. Serra, São Paulo, Ed. PINI, 2000.

[9] QUARCIONI, V. A. "Influência da cal hidratada nas idades iniciais da hidratação do cimento Portland: 
estudo em pasta”, Tese de D.Sc., Escola Politécnica, Universidade de São Paulo, São Paulo, 2008.

[10] SOUZA, A. F. "Otimização do uso de aditivos estabilizadores de hidratação do cimento em água de lavagem dos caminhões-betoneira para a produção de concreto", Dissertação M.Sc., Programa de PósGraduação em Engenharia Civil, Universidade Federal de Santa Catarina, Brasil, 2007.

[11] HASTENPFLUG, D. "Emprego de aditivos em pasta de cimento para poço de hidrocarbonetos e injeção de CO2: Influência na resistência à degradação por ataque ácido", Tese de D.Sc., - Programa de PósGraduação em Engenharia e Tecnologia de Materiais, Pontifícia Universidade Católica do Rio Grande do Sul, Brasil, 2012.

[12] TAYLOR, H. F. W. Cement Chemistry, Londres, Academic Press, 1990.

[13] SANDBERG, P., LIBERMAN, S. (2007). "Monitoring and evaluation of cement hydration by semiadiabatic field calorimetry", In: K. Wang and A. K. Schindler, Eds. Concrete Heat Development: Monitoring, Prediction, and Management, Georgia 22-26 April 2007. NY: Curran Associates, Inc., 13-24.

[14] RAMACHANDRAN, V.S. (ed.). Concrete admixtures handbook : properties, science, and technology, Park Ridge, Noyes, 1984.

[15] JAWED, I., SKALNY, J., YOUNG, J.F. Hydration of portland cement. in: structure and performance of cements, Ed. Barbes, P. Applied Science Publishers, London, 1983

[16] WEAKLEY, R. W. "Evaluation of Semi-Adiabatic Calorimetry to Quantify Concrete Setting". Auburn, Alabama, Dissertação M.Sc., Faculty of Auburn University, USA, 2010.

[17] ASSOCIAÇÃO BRASILEIRA DE NORMAS TÉCNICAS. NBR NM 43: Cimento Portland - Determinação da pasta de consistência normal. Rio de Janeiro, 2003. 